BMJ Open

Sport \&

Exercise

Medicine

\title{
Managing the return to sport of the elite footballer following semimembranosus reconstruction
}

\author{
Matt Taberner (D), ${ }^{1}$ Fares S Haddad, ${ }^{2,3}$ Andy Dunn, ${ }^{4,5}$ Adam Newall, ${ }^{6}$ Lloyd Parker, ${ }^{1,7}$ \\ Esteban Betancur, ${ }^{8}$ Daniel D Cohen (D) 8,9
}

To cite: Taberner M, Haddad FS, Dunn A, et al. Managing the return to sport of the elite footballer following semimembranosus reconstruction. BMJ Open Sport \& Exercise Medicine 2020;0: e000898. doi:10.1136/ bmjsem-2020-000898

- Supplemental material is published online only. To view please visit the journal online (http://dx.doi.org/10.1136/ bmjsem-2020-000898).

Accepted 26 September 2020

Check for updates

(C) Author(s) (or their employer(s)) 2020. Re-use permitted under CC BY-NC. No commercial re-use. See rights and permissions. Published by BMJ.

For numbered affiliations see end of article.

Correspondence to

Matt Taberner;

matthewtaberner@btinternet.com

\section{ABSTRACT}

Hamstring strains are the most common injury in elite football and typically occur during high-speed running. Despite its important contribution to power production in the late swing phase, injury to the semimembranosus (SM) is less common than to the biceps femoris, but may involve the free tendon and depending on the degree of retraction, warrant surgical repair. Few case reports detail clinical reasoning, supported by objective data during rehabilitation in elite footballers, and none have described the return to sport (RTS) process following this type of hamstring injury. In this article, we outline the management and RTS of an English Premier League (EPL) footballer who suffered a high-grade SM proximal tendon tear during training. Due to the degree of retraction of the free tendon, the player underwent surgical reconstruction at the recommendation of an orthopaedic surgeon. Early physiotherapy care, nutritional support, on- and off-pitch injury-specific reconditioning and global athletic development are outlined, alongside strength and power diagnostic and global positioning systems data, assessment of pain, player feedback and MRI informed clinical reasoning and shared decision-making during the RTS process. 18 weeks postsurgery the player returned to team training, transferring to a new club 3 weeks later. 2.5 years post RTS, the player remains free of re-injury playing regularly in the EPL.

\section{CASE SCENARIO}

Hamstring injuries are the most prevalent in elite football and the biceps femoris long head (BFlh) the most frequently injured muscle. ${ }^{1}$ Injury to the BFlh typically occurs during highspeed running (HSR) as the muscle undergoes high strain. Despite its important contribution to force production during the late swing phase of maximal speed running, injuries to the semimembranosus (SM) are less frequent, and tend to occur in slow stretch type activities. ${ }^{2}{ }^{3}$ This type of injury may also involve a degree of retraction of the proximal free tendon, which may warrant surgical intervention. ${ }^{3}$

In this article, we outline the management and return to sport (RTS) of an English Premier League (EPL) footballer who suffered a high-grade SM proximal free tendon tear (figure 1). The injury occurred during training as he overstretched stepping over the ball.
Key points

- Semimembranosus injuries tend to occur during slow stretch type activities and may involve the free tendon. Depending upon the upon the degree of tendon retraction, these injuries may warrant surgical repair.

- Off-pitch rehabilitation progressively integrated high-intensity isometrics, high strain eccentrics and exercises requiring intermuscular coordination - emphasising involved limb loading. Alongside reconditioning specific to the injury, rehabilitation also provided a 'loading opportunity' to integrate jump-landing activities to improve the player's overall athletic qualities.

- On-pitch rehabilitation followed the 'control-chaos continuum' considering important factors specific to hamstring injury; positional-specific conditioning, progressive exposure to HSR volume and maximal speed running under increasingly chaotic conditions.

- Communication and a player-centred shared decision-making process involving external healthcare professionals and a multidisciplinary team help to ensure optimal player care during RTS

Surgical repair was required, and 18 weeks post-injury, the player returned to team training. Two and a half year's post RTS, he is playing regularly in the EPL without re-injury. There are few case reports in the literature describing the rehabilitation and RTS of elite footballers in detail and none following this type of hamstring injury. We share the player's pre-injury and RTS running loads, strength and power (S\&P) diagnostic data, on- and off-pitch physical preparation, and the clinical reasoning and considerations involved in the decision-making process.

\section{DECISION-MAKING PROCESS LEADING TO SURGERY}

As the post-injury MRI revealed a retracted tear (figure 2A and table 1), an orthopaedic surgeon recommended an operative approach over the conservative option which was deemed to present a greater risk of re-injury, extending 


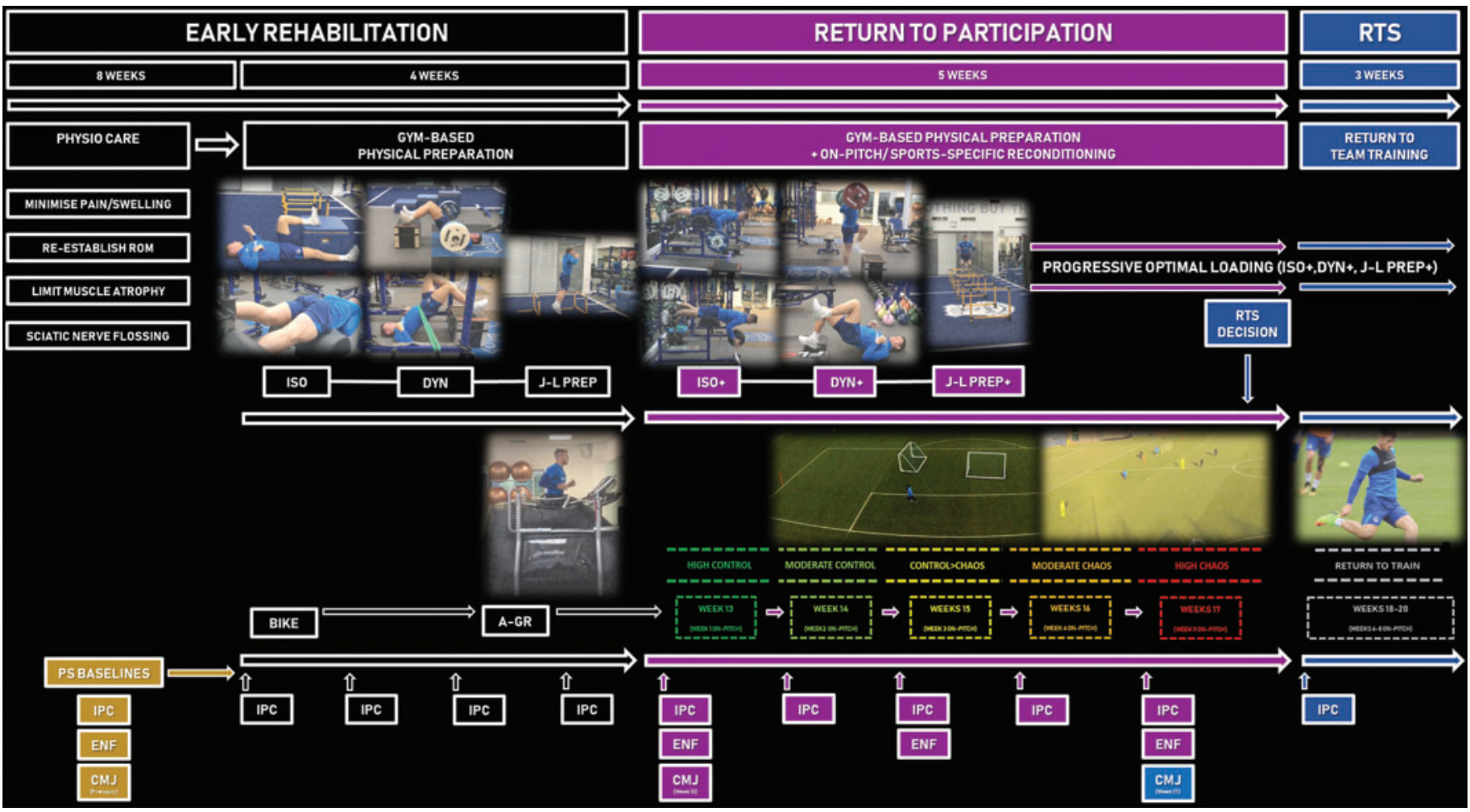

Figure 1 Overview of the return to sport (RTS) of an elite male football player following semimembranosus free tendon reconstruction. Early rehabilitation is divided into two phases: physiotherapy care (Weeks 1-7) and transition into gym-based physical preparation (Weeks 8-12) including isometrics (ISO), dynamic strength (DYN) and jump-landing preparation (J-L Prep) and progression from stationary bike to anti-gravity treadmill running (A-GR) (Alter-G, Fremont, CA, USA). Return to participation phase (Weeks 13-17); on-pitch sports-specific reconditioning using the 'control-chaos continuum' (weeks displayed on-pitch) plus progression (+) of gym-based physical preparation; ISO+, DYN+ and J-L Prep+. RTS decision=return to team training (Weeks 18-20; return to train) and continued progressive optimal loading with reduced volume (sets) of ISO+, DYN+ and J-L Prep+. Arrows indicate timepoints of isometric posterior chain (IPC), eccentric knee flexor (ENF) and countermovement jump (CMJ) assessments. Data from these strength and power diagnostic tests, quantifying neuromuscular deficits relative to his healthy preseason (PS) values, and his response to on- and off-pitch reconditioning, informed exercise and phase progression decisions.

RTS and potentially placing the player's career in jeopardy. Progressing with a conservative approach would have increased the formation of scar tissue and resulted in a loss of tension within the SM. This would be expected to have profound consequences for an elite footballer, in terms of the decreased ability to generate force, power and run at high-speeds, and potential increased risk of injury to other hamstring musculature due to compensatory demands. Furthermore, delaying surgery or operating on a scarred tissue bed would increase the challenge of restoring anatomy. ${ }^{4}$

The procedure was undertaken under general anaesthesia (prone position). A longitudinal incision is necessary to access these tears, allowing tracking into the medial window between the hamstring and adductor compartments. The SM injury lies next to the sciatic nerve and the tendon tends to tear in a staggered way so there is one segment still connected to the membrane and muscle distally and one segment connected to the tendon insertion proximally. The two segments are identified, the sciatic nerve and its branches protected. The two tendon ends are re-approximated to the correct level of tension, assessed by restoring anatomy and held together with Ethibond non-dissolving sutures which hold in situ long enough for the tendon to heal. These are reinforced with Vicryl dissolvable sutures to regain the appropriate tendon length (restore pre-injury length) and to provide tensile strength. The repair is then tested by manual pressure and by applying stretch to the hamstring musculature.

Nutritional considerations following muscle-tendon injury

Nutritional support had two principal aims

- to minimise muscle atrophy by maintaining caloric intake, ${ }^{5}$ taking creatine $(5 \mathrm{~g})$ and $3 \mathrm{~g}$ omega-3 poly-unsaturated fatty acid supplements $(750 \mathrm{mg}$ docosahexaenoic acid, $1500 \mathrm{mg}$ eicosapentaenoic acid) ${ }^{6}$ and to promote maximal muscle protein synthesis by consuming approximately $35 \mathrm{~g}$ every 3 hours (5/day) to achieve a protein intake of $\sim 2 \mathrm{~g} / \mathrm{kg} / \mathrm{BM}(170 \mathrm{~g}){ }^{6}$ Daily energy intake, monitored by 24-hour dietary recall and analysed using a nutritional software package (Nutritics, v5, Ireland), was estimated to be $\sim 3000 \mathrm{kcal}$.

to promote tendon healing. Beginning at 8 weeks post-surgery, an hour before activity the player consumed a collagen $(20 \mathrm{~g})$ and vitamin C (80 mg) supplement shown to be beneficial for tendon remodelling. 


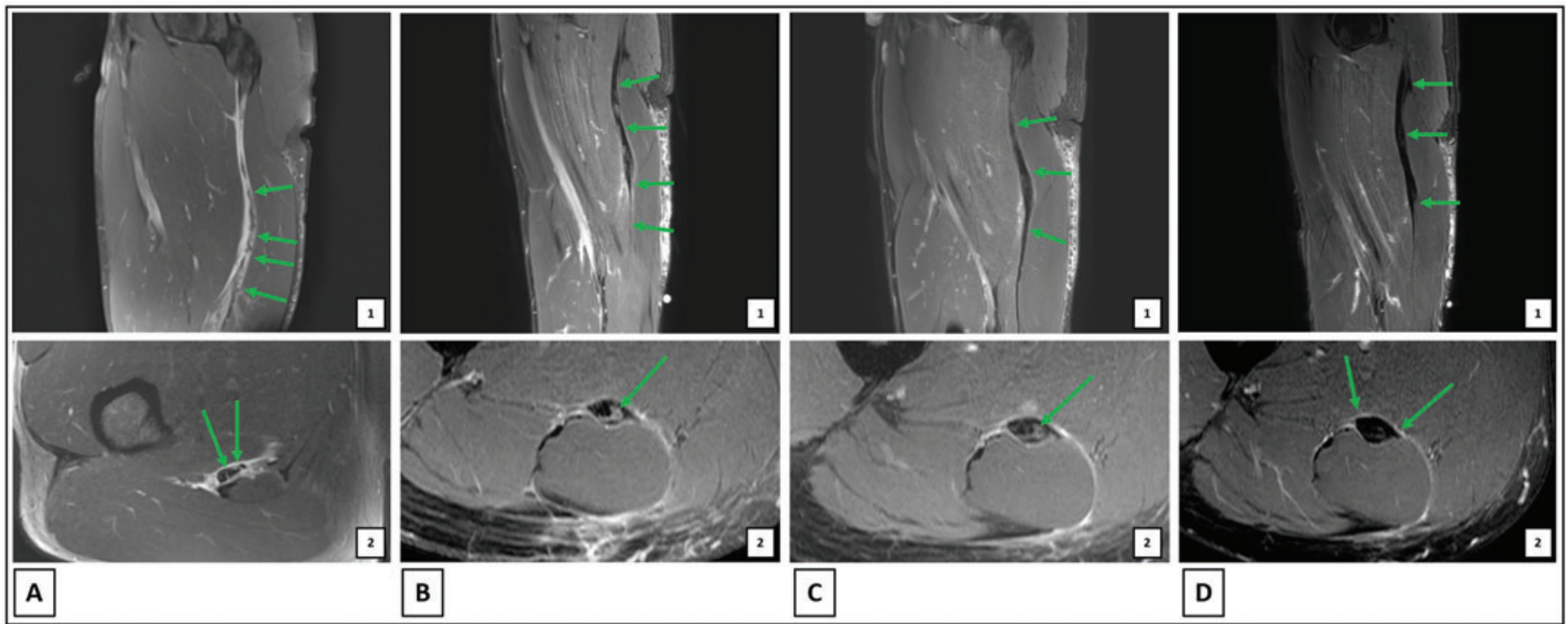

Figure 2 MRI throughout the return to sport process. Green arrows indicated key prognostic features. (A) 24 hours post-injury: (1) semimembranosus (SM) free tendon laxity and muscle retraction, (2) longitudinal split tearing at SM tendon origin. (B) 7 weeks post-surgery: (1) normal SM tendon/myotendinous junction tension, (2) maturing granulation tissue in SM tendon repair site. (C) 11 weeks post-surgery: (1) segmental tendon thickening and restoration of tension, (2) intratendinous maturing fibrous scar tissue. (D) 17 weeks post-surgery: (1) continued maturation of scar tissue throughout the site of surgical repair of the free proximal extra muscular portion of the SM tendon, (2) long segment of tendon repair shows relatively uniform low signal intensity scarring and maintains normal tension throughout the extra muscular portion and the proximal intramuscular portions of the tendon.

\section{MECHANICAL LOADING AND RTS}

An MRI 7 weeks post-surgery, following early post-surgical physiotherapy management, showed a good healing response (table 1; figures 1 and 2B). Reconditioning then began under sports science supervision, with daily communication including pain response (numerical rating scale; NRS) and periodic checks of the player with the club physiotherapist (table 1). Submaximal isometrics (at 60-90 ${ }^{\circ}$ knee flexion) were introduced in Week 7 and a week later the player performed his first postinjury unilateral isometric posterior chain (IPC) test (figure 3). ${ }^{89}$ The IPC test was used to quantify the players' ability (and willingness) to produce maximal force (IPC peak force', IPC-PF) and early rate of force development (RFD) (force at $100 \mathrm{~ms}$ ). ${ }^{10}$ Week 8 interlimb asymmetry (ILA) in IPC-PF was $13 \%$ and in force at $100 \mathrm{~ms}$ was $7 \%$. While the force at $100 \mathrm{~ms}$ ILA was low relative to that of IPC-PF, this should be considered in the context of the substantially larger magnitude declines in force at $100 \mathrm{~ms}$ than peak force on both limbs (figure 4). These data highlight both the importance of evaluating RFD -related variables following injury and of having healthy benchmark values to reduce the dependence on \% ILA as a marker of status and progress. ${ }^{11} 12$

Exercise selection and programming was based on the optimal loading concept — to maximise physiological adaptation of the involved structures. ${ }^{13}$ Isometrics were the predominant mode of strength training during initial programming, with the conceptual aims of increasing tendon stiffness and enhancing maximal force development. $^{14} 15$ Programming began with unilateral short-lever overcoming isometrics at $90^{\circ}$ hip and knee flexion (figure 5; single-leg (SL) heel drives - knee dominant; online supplemental video 1) to bias medial hamstring recruitment. ${ }^{9}$ While this exercise remained key prior to gym-based rehabilitation sessions to 'prime' the injury site, progression involved integrating long-lever yielding isometric variations such as doubleleg isometric hip extension, followed by its SL derivative - hip dominant, with knee involvement as the hamstring is elongated (figure 5). ${ }^{16}$ We used $>80 \%$ of maximal voluntary contraction - the threshold to stimulate the development of mechanical and material tendon properties $^{17}$ and programmed in clusters (3-5× 3-5 s isoholds), to develop maximal strength, RFD and strengthendurance. $^{15} 18{ }^{19}$ We delayed integrating high strain eccentric exercises in the initial 2 weeks of reconditioning to avoid excessive mechanical strain on the healing structures. $^{20}$ Furthermore, post-injury inhibition is reported during bilateral eccentric loading, potentially compromising adaptations, ${ }^{21}$ whereas maximal isometrics elicit higher voluntary muscle activation and lower inhibition. ${ }^{22}$

With no pain reported $(<2 / 10$ NRS) following early isometric loading, we added dynamic strength exercises, coaching 'intent' ${ }^{23}$ to move as explosively as possible to develop power, with the conceptual goals of promoting collagen synthesis, fibre alignment and improving tendon-tensile strength. ${ }^{24-26}$ We first introduced the heel elevated hip thrust (hip dominant, with the hamstrings 


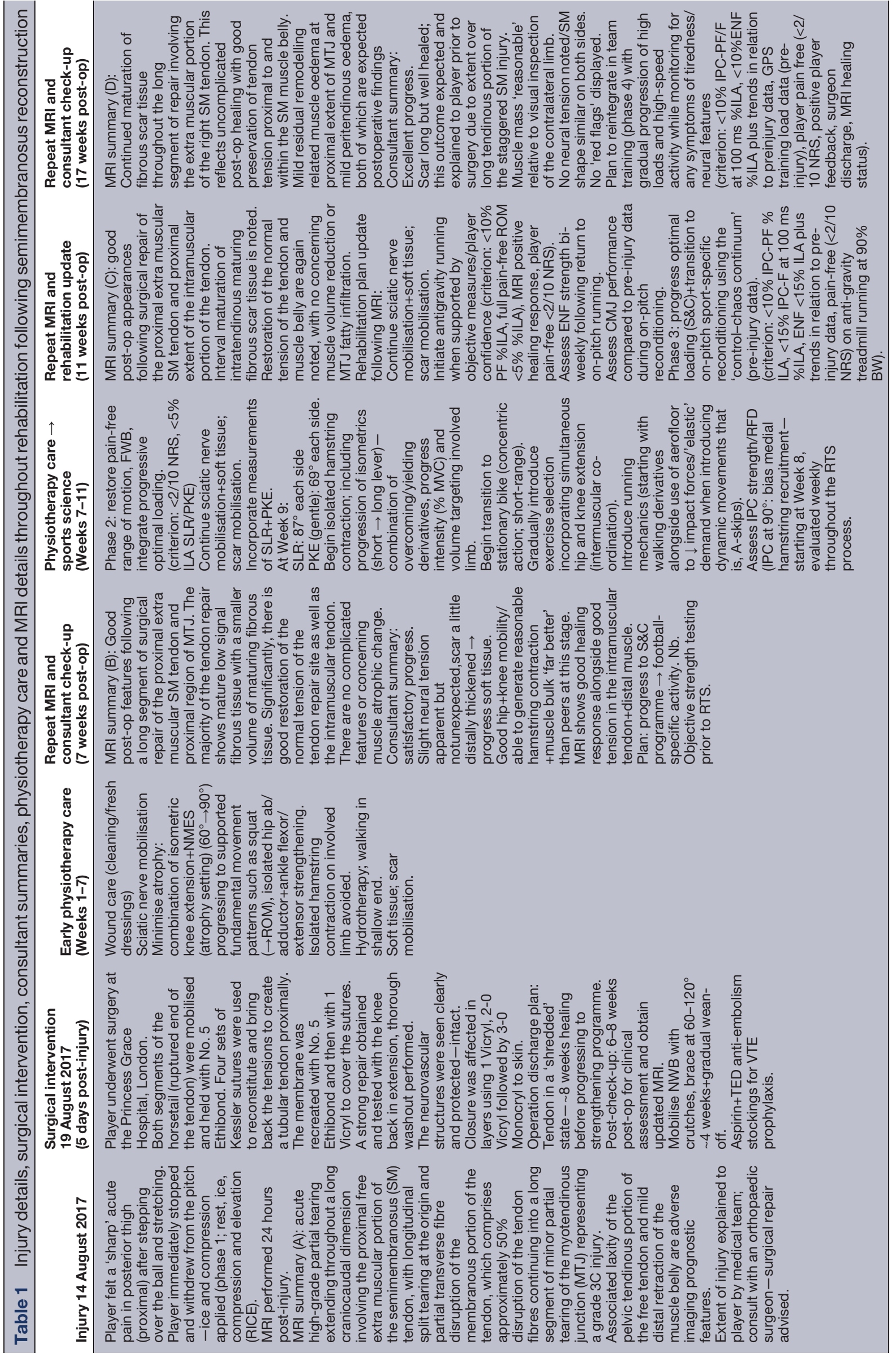

늠. 잉

نे

응 음

额

要 象

하

ब.

\% 용

응 옹

등

ह 잉

空

O

䙹

हैं क

है ญ

ํํำ

है

힘을

.

응

$\geq \omega$

하워

응

बळ $\overline{0}$ 응

는 응

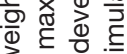

तo 0

इ인

mi

유 $\frac{d}{0}$

के की

产

\& 으

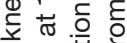

을 월

के 눙

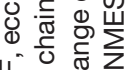

岂흔

i

बू वे

这. 잉

$\rightarrow \varepsilon$

बं

U है

응응 웡

है 产

品 5

ब․ㅠ

बैं

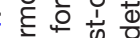

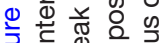
흔 규웡ㅇㅇㅇ $=7$ 品 ₹ $\sum_{0} 0$ 잉 क的部崖

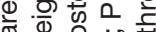

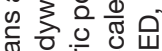

का 응 을

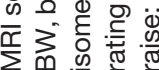




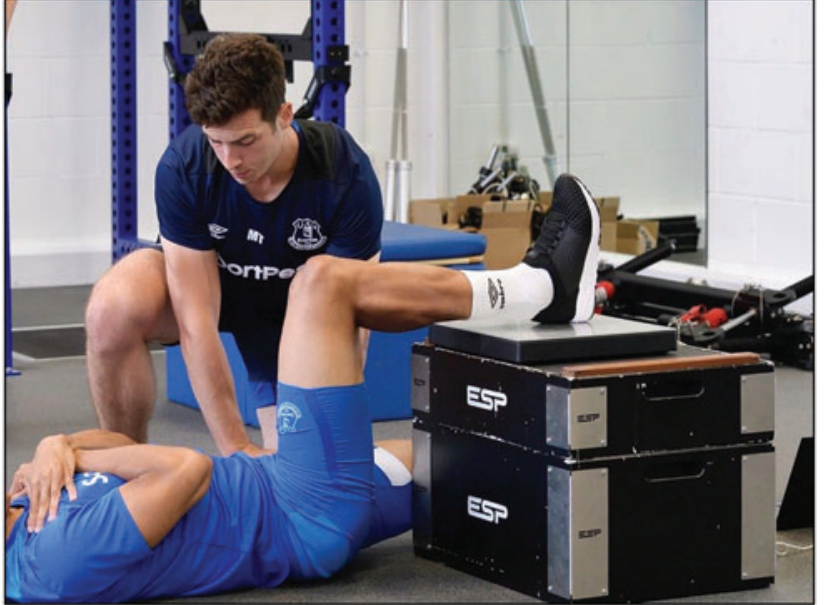

Figure 3 Isometric posterior chain (IPC) test performed using a portable force platform at $1000 \mathrm{~Hz}$ (PS-2141, Pasco, Roseville, CA, USA) with proprietary software (ForceDecks, Vald Performance, Brisbane, Australia). Test performed with the player lying supine position, the heel of the testing limb placed on the force platform resting on a firm plinth with the testing angle set at $90^{\circ}$ hip and knee flexion using a goniometer (Physio Parts, Twickenham, UK) and the non-testing limb relaxed and fully extended. The player was instructed to push the heel of the testing limb into the force platform exerting as much force as fast as possible while keeping the buttocks, hips and head on the mat and hands crossed on chest. External pressure was applied to the non-tested pelvis/hip to prevent hip extension. The player was familiar with the test, but standardised instructions were given before the assessment, a verbal command of ' 3 , 2, 1 GO' countdown before the initiation of a maximal effort contraction which was held for $3 \mathrm{~s}$ during which consistent verbal encouragement was given 'PUSH, PUSH, PUSH, RELAX'. Three maximal voluntary contractions were performed with $10 \mathrm{~s}$ rest between repetitions.

acting isometrically to resist knee extension) and the split squat (hip and knee hybrid), subsequently progressed with external load, and increasing exercise complexity to provide additional challenges to the neuromuscular system (figure 5). ${ }^{13}$ A positive response to these explosively performed dynamic hip dominant exercises alongside progressive high-intensity isometrics may be apparent in the IPC response 2 weeks (Week 11) later. IPC force at $100 \mathrm{~ms}$ showed large increases in both limbs, although greater on the non-involved side, while improvements in IPC-PF were smaller but favoured the involved limb. High strain eccentrics were now introduced, and to emphasise bi-articular loading and medial hamstring recruitment, we selected the sliding leg curl (SLC), ${ }^{27}$ later progressed to the SL derivative to increase involved limb overload (online supplemental video 2). ${ }^{28}$ Slow-stretch shortening cycle (SSC) jump-landing activities were now added, to enhance the global athletic qualities of lower-limb stiffness, neuromuscular control and power. ${ }^{29}$

\section{PROGRESSING TO ON-PITCH REHABILITATION}

At 12 weeks post-surgery, with 10\% ILA in IPC-PF and follow-up MRI showing further positive healing response (table 1; figures $2 \mathrm{C}$ and 4), the player initiated $70 \%$ bodyweight anti-gravity treadmill running (AG-R), progressing to $90 \%$ bodyweight (completing three sessions during Week 12; 70\%, 80\% and $90 \%$ bodyweight) (online supplemental video 3 ). Prior to each AG-R session, the player performed a series of running mechanic drills including A-skips and straight-leg bounds to replicate the co-ordination demands and proximal-distal energy sequencing associated with running (figure 5). ${ }^{30}$ These drills were also implemented within on-pitch warm-ups alongside drills to develop acceleration and deceleration qualities. At Week 12, IPC-PF ILA was $<10 \%$, IPC force at $100 \mathrm{~ms}$ ILA was $14 \%$, and to further inform clinical reasoning and decision-making at 13 weeks, we also assessed ENF strength, the player showing $11 \%$ ILA as well as ENF force substantially above threshold prospectively associated with elevated hamstring injury risk (figure 4). ${ }^{31}$ We considered that these data provided evidence to support our clinical judgement that the level of risk tolerance was above the level of risk exposure and did not warrant a delay in initiating the high control phase of the 'control-chaos continuum'. 32 The goal of this phase was to expose the player to submaximal running speeds $(<60 \%$ preinjury maximal speed) monitored using global positioning systems, promoting neuromuscular recovery in preparation for $\mathrm{HSR}^{33}$ and to build player confidence in his return to on-pitch activities. The similar improvements in IPC-PF and IPC force at $100 \mathrm{~ms}$ in the involved limb between Weeks 13 and 14 (figure 4) suggested a positive response to the initial exposure to the return to running phase and lack of load involved limb avoidance in on-pitch activities. Consequently, in Week 14, we progressed to a low dose of 'controlled' HSR (within-session 0.30 gameload HSR) alongside the introduction of directional change load and technical skill integration (figures 4 and 6). Prior to beginning Week 3 of on-pitch reconditioning (Week 15 post-surgery), IPC \%ILAs (in PF and force at 100 $\mathrm{ms}$ ) were $<10 \%$ and involved limb IPC-PF and ENF strength increases of $\sim 15 \%$ since Week 13 (figure 3). This gave us confidence in implementing a progressive increment in 'controlled' HSR volume through aerobic power conditioning (online supple mental video 4) alongside more chaotic activities phase-specific pass and move, and positional acceleration drills, in the transition to football-specific weekly periodisation. $^{32}$ Off-pitch conditioning progressed (online supplemental videos 5 and 6), increasing movement velocity emphasis (online supplemental videos 7 and 8) (figure 5). Additionally, due to the stretch mechanism of the injury in which hip flexion combined with an inability to control knee extension, we considered the barbell split squat with forward lean 


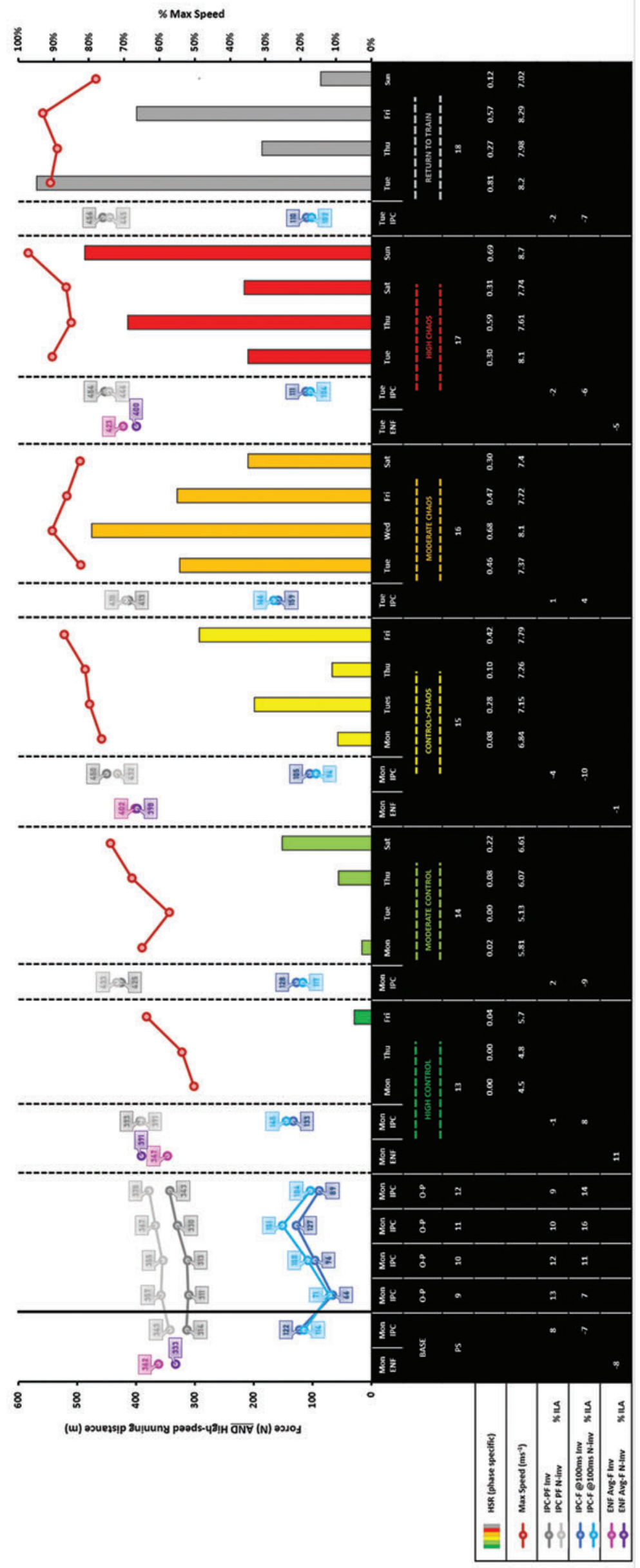

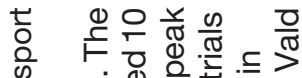

i $\frac{0}{0}$ 유

눙

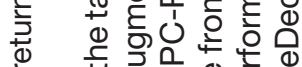

\%

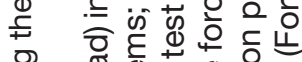

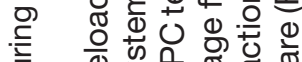

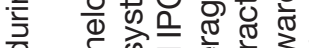

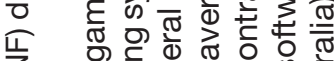

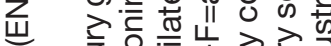

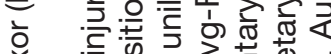

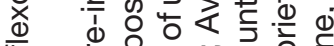

흐은

융 드응

을

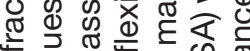

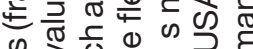

\% $>$ O

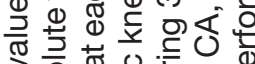

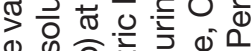

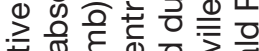

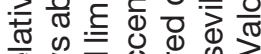

잉엉

음

क क क

क $\frac{0}{0}$.

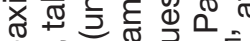

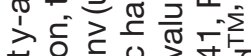

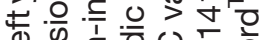

ब)

के

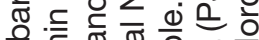

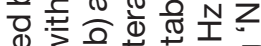

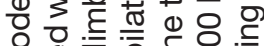

0 造言

郭

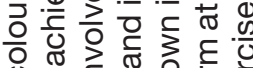

Oํ.

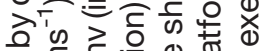

응 $\stackrel{2}{\underline{E}}$.

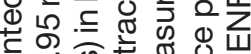

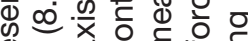

क

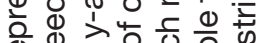

ब

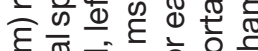

क

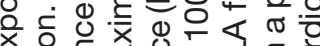

ब。

ఫ্

के

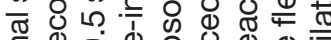

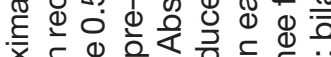

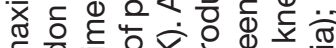

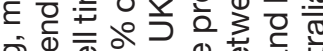

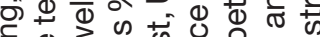

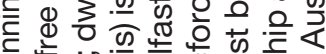

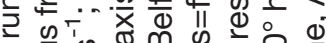

유 कू है क

ष

कि 훈

는슬 की

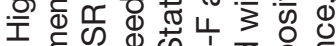

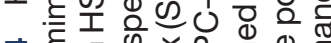

म ह

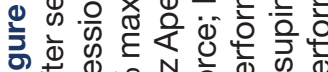

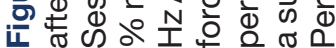



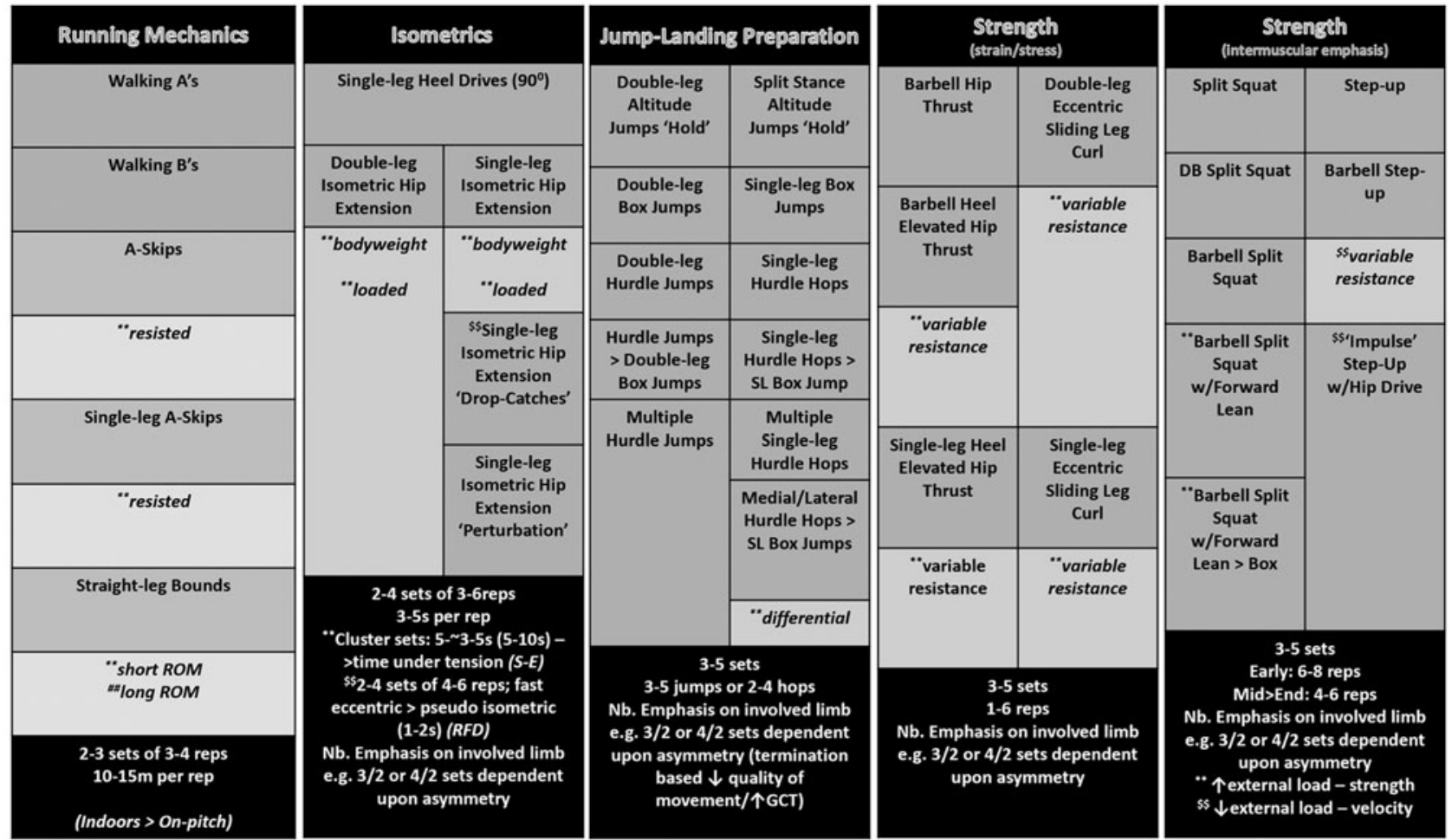

Figure 5 Optimal loading approach following semimembranosus free tendon reconstruction during the early rehabilitation phase onwards; gym-based physical preparation (Weeks 8-20). Running mechanics prior to anti-gravity treadmill running and implemented during on-pitch rehabilitation warm-ups. Dark grey=exercise, Light grey=exercise derivative. Strength (strain/stress) and (intermuscular emphasis)=dynamic strength training. w/=with, $\uparrow=$ increase, $\downarrow=$ decrease, =circa, > progression/onto. DB, dumbbell; early, early-stage; end, end-stage; GCT, ground contact-time; mid, mid-stage; Nb., note; reps=repetitions; RFD, rate of force development; ROM, range of motion; S-E, strengthendurance.; SL, single-leg.

a key exercise (online supplemental video 9$),{ }^{34}$ progressed using external load and increasing exercise complexity (figure 4). Accommodating resistance was also added to the SL eccentric SLC to increase the speed and strain rate of eccentric loading ${ }^{72}$ while fast SSC plyometric activities were also integrated into the player's programming (online supplemental video 10) (figure 5). We took advantage of this period to integrate conditioning aimed at developing the capacity to rapidly decelerate the centre of mass and follow with rapid increases in concentric force, power, ${ }^{32}$ explosive and reactive qualities important to the player's playing characteristics.

Our S\&P diagnostic criterion for progression to the moderate chaos phase ${ }^{29}$ was an IPC-PF and IPC force at $100 \mathrm{~ms}$ ILA $<10 \%$ and stable outputs (lack of regression) in response to the control to chaos phase (figure 4). The transition to the moderate and high chaos phases is important as it exposes the player to substantially higher cumulative weekly HSR, and subsequently progressing to HSR loads reflecting game output, progressively higher maximal speed exposure, alongside positional requirements and technical skill components (figures 4 and 6; online supplemental videos 11 and 12). ${ }^{10} 32$ Pre-injury running load and HSR volumes used to plan running load targets were based on player outputs under the previous manager's regime. However, we anticipated higher team training loads under the new regime and therefore aimed to return the player to his maximum cumulative training HSR volume to adequately prepare the player for these demands (figure 6). As an attacking midfielder, it was important to include additional shooting practice in the moderate and high chaos phases to mitigate injury risk associated with inadequate exposure to ball-striking (online supplemental video 13). ${ }^{35}$ Based on a combination of objective injury-relevant S\&P and training load data (figures 4 and 6), MRI results highlighting healing and maturation (figure 2D), the surgeons' positive opinion (table 1), and positive feedback/lack of pain reported by the player, we concluded that the players' level of risk tolerance was above estimation of re-injury risk, and 18 weeks post-surgery, the player resumed team training. Furthermore, comparing the player's countermovement jump profile to that of pre-injury suggested a positive response to the off- and on-pitch loading (figure 7). Notably, at Week 17 despite modest deficits in jump height $(5 \%)$ and peak power 


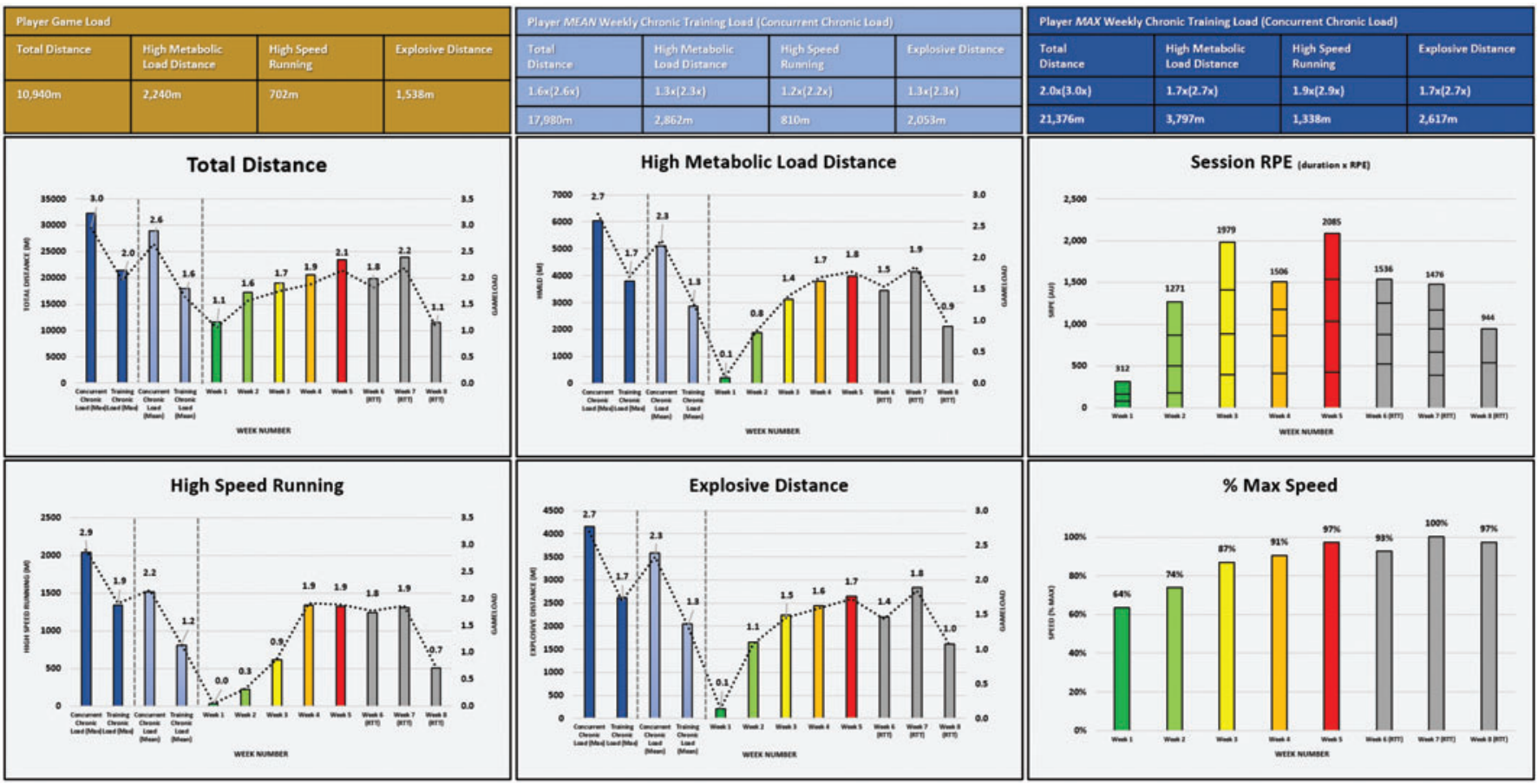

Figure 6 Return to chronic running loads following semimembranosus free tendon reconstruction using the 'control-chaos continuum' as a framework for return to sport. Tables show the player's pre-injury 'gameload' running load metrics from season 2016/2017. Total distance (TD), high-speed running $(H S R)=>5.5 \mathrm{~ms}^{-1}$, explosive distance $($ Exp-D)=accelerating/decelerating from $2 \mathrm{~ms}$ to $4 \mathrm{~ms}^{-1}<1 \mathrm{~s}$, high metabolic load distance=distance above $25 \mathrm{w} \bullet \mathrm{kg}^{-1}$; HSR plus Exp-D). Gold box are absolute values. Light blue and dark blue boxes show relative (multiples of) gameload (ie, $2 x=2$ games worth) and absolute, mean and max training and concurrent (training plus game), respectively.

Weekly absolute (left y-axis) and relative (right y-axis) TD, high metabolic load distance, HSR and Exp-D are shown for each week of on-pitch rehabilitation in graphs. Session rate of perceived exertion (session-RPE) (y-axis=arbitrary units) shows weekly accumulated session-RPE (training session duration (min) $\times$ RPE). \% max speed=(maximum speed achieved in session/player's pre-injury maximal speed $\left.\left(8.95 \mathrm{~ms}^{-1}\right) \times 100\right)$. Control-chaos continuum: Control; high influence on behaviour/actions/movement-controlled situations. Chaos; behaviour/actions/movement, unpredictable/ random/reactive - chaotic situations. Green=high control, pale green=moderate control, yellow=control to chaos, orange=moderate chaos, red=high chaos and grey=return to team training (RTT). Global positioning systems; augmented $10 \mathrm{~Hz}$ Apex (StatSports, Belfast, UK).

(7\%), relative to pre-injury, suggestive of performance decline secondary to the injury/deconditioning, there were substantial improvements in strategy/kinetic variables such as eccentric deceleration RFD (20\%), concentric impulse-100 (8\%) and lower limb stiffness $(13 \%)$, indicative of improved SSC ability. ${ }^{11} 36$ Importantly, at this time point, the player had achieved $97 \%$ of pre-injury maximal speed (figures 4 and 6), without full recovery of aspects of neuromuscular performance, and several weeks remained before expected return to competition to further recover these.

In the first week following return to team training (online supplemental video 14), within-session HSR increased (a 0.12 gameload increase from previous max rehabilitation session) while cumulative HSR was within his range of chronic weekly volume and other running load markers monitored across the playing squad (figure 6). Importantly, the player communicated that he felt the demands of team training were below that of rehabilitation (figure 6), suggesting he was adequately prepared to cope with a return. Within 2 weeks of his RTS, the player was the subject of a bid from another EPL team competing within the UEFA Champions League. Twenty weeks post-surgery and following 11 team training sessions, he passed a medical and a transfer was agreed.

\section{SUMMARY}

Following surgery and early care management, on- and off-pitch loading stimuli were progressively integrated with global positioning systems and S\&P diagnostics used to quantify running load and monitor player neuromuscular status, respectively. This objective data, in conjunction with clinical experience from several sources and player feedback, informed decisions on phase and loading progression to raise the level of risk tolerance and ultimately facilitate a successful outcome for club and player. 

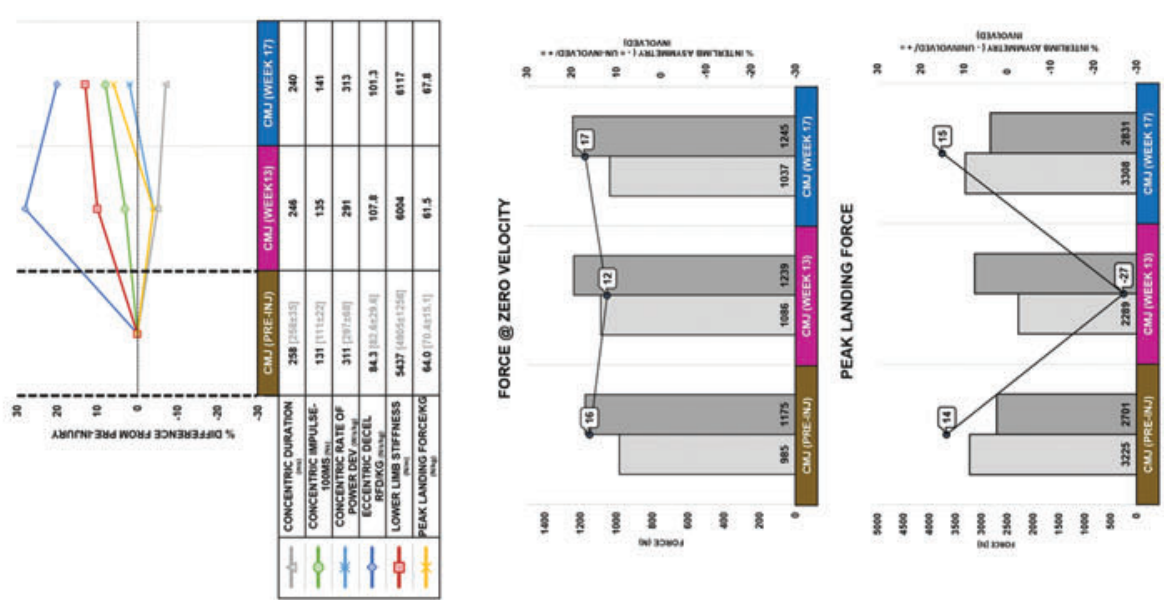

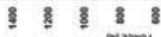

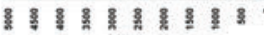

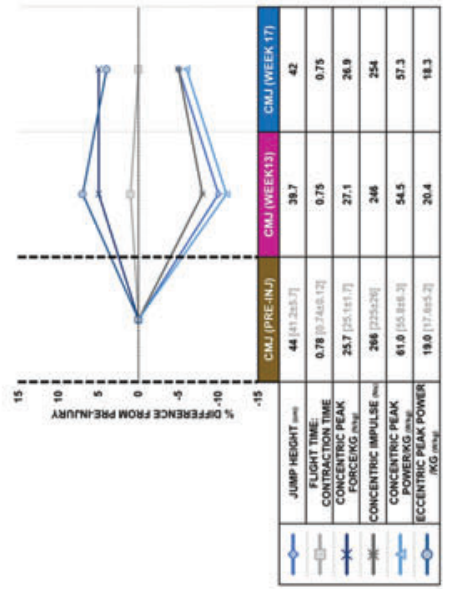

0

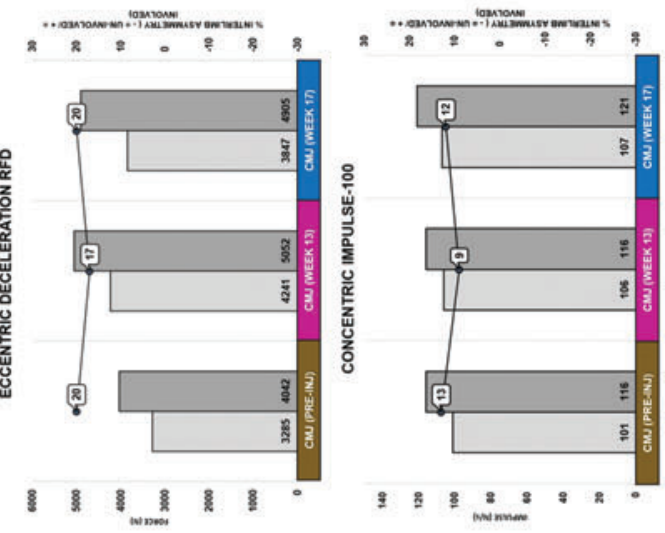

\section{0}

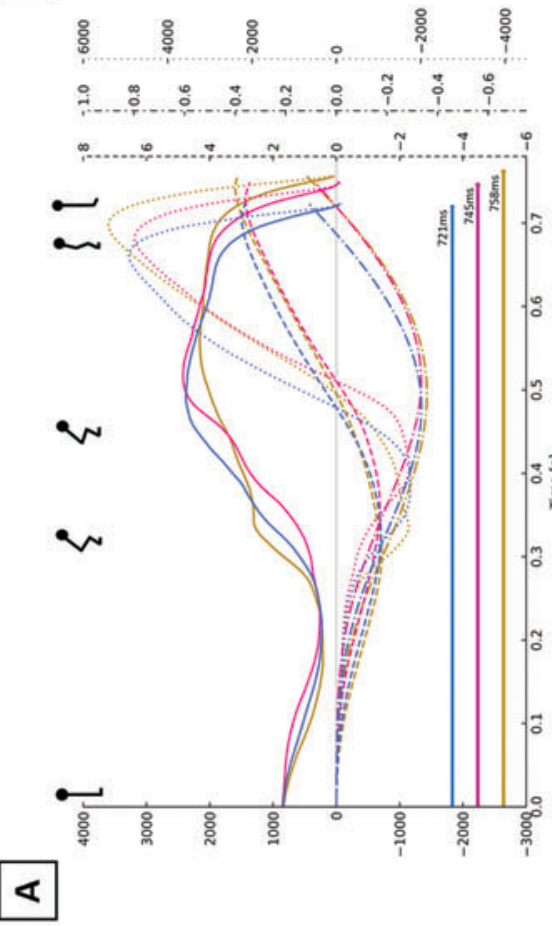

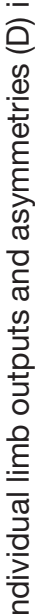

(ब ब $\frac{5}{2}$ 응

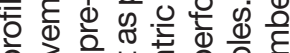

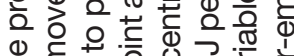

है

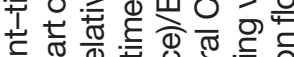

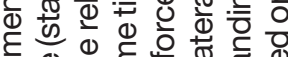

ब

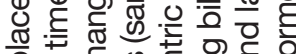

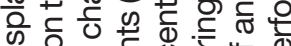

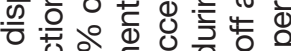

की

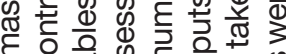

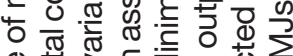

(1) 苟 $>$

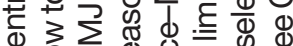

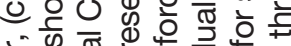

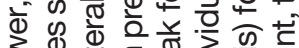

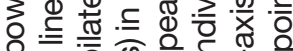

응

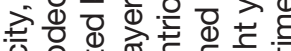

엉 웡ㅎㅇ 응 은

خ

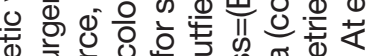
๑

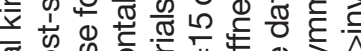

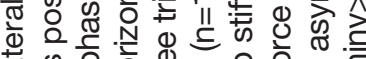

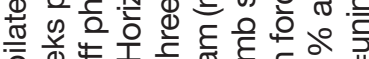

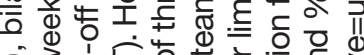

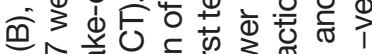

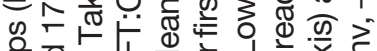
응 ত

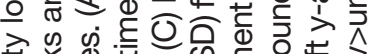
言㐫 क

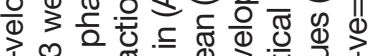

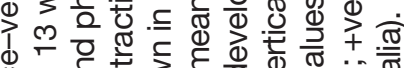
d广

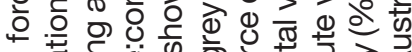

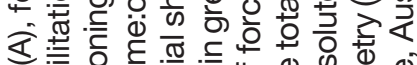
क

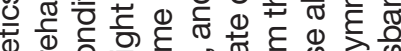
ब ब 立

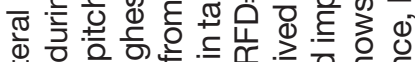

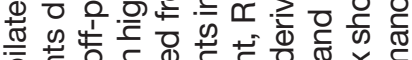

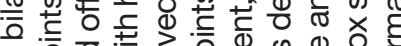

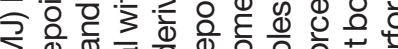

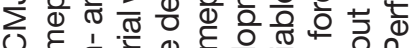
U.

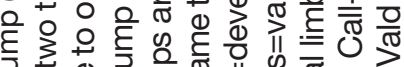

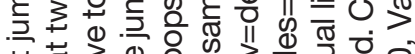

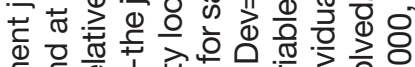

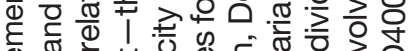
ข

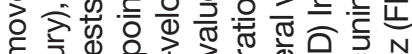

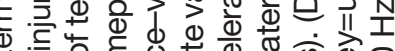
ब

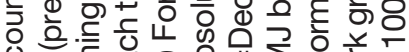
ช.

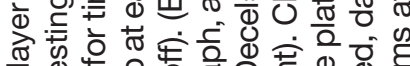
뜬

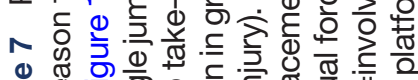
인 8 뉸

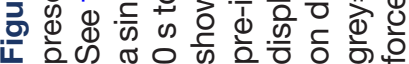




\section{Author affiliations}

${ }^{1}$ School of Sport and Exercise Sciences, Liverpool John Moores University, Liverpool, UK ${ }^{2}$ University College London Hospitals NHS Foundation Trust, London, UK

${ }^{3}$ Institute of Sport, Exercise and Health, London, UK

${ }^{4}$ Royal Liverpool and Broadgreen University Hospitals NHS Trust, Liverpool, UK

${ }^{5}$ The OrthTeam, Spire Healthcare Ltd, Manchester, UK

${ }^{6}$ Medical Department, Everton Football Club, Liverpool, UK

${ }^{7}$ Nutrition Department, Everton Football Club, Liverpool, UK

${ }^{8}$ Sports Science Center (CCD), Colombian Ministry of Sport (Mindeporte), Colombia

${ }^{9}$ Masira Research Institute, Universidad de Santander, Bucaramanga, Colombia

Twitter Matt Taberner @MattTaberner, Lloyd Parker @parkernutrition and Daniel cohen @daniecohen1971.

Contributors FSH surgically operated on the player, AD provided MRI reports, AN provided physiotherapy care, LP provided nutritional support, MT led on- and off-pitch physical preparation, planned and wrote the manuscript, DC provided assistance writing the manuscript and feedback. MT, DC and EB provided an analysis of S\&P diagnostics.

Funding This research received no specific grant from my funding agency in the public, commercial or not-for-profit sectors.

Competing interests None declared.

Patient consent for publication Obtained (BMJ consent form).

Provenance and peer review Not commissioned; externally peer reviewed.

Supplemental material This content has been supplied by the author(s). It has not been vetted by BMJ Publishing Group Limited (BMJ) and may not have been peerreviewed. Any opinions or recommendations discussed are solely those of the author(s) and are not endorsed by BMJ. BMJ disclaims all liability and responsibility arising from any reliance placed on the content. Where the content includes any translated material, BMJ does not warrant the accuracy and reliability of the translations (including but not limited to local regulations, clinical guidelines, terminology, drug names and drug dosages), and is not responsible for any error and/or omissions arising from translation and adaptation or otherwise.

Open access This is an open access article distributed in accordance with the Creative Commons Attribution Non Commercial (CC BY-NC 4.0) license, which permits others to distribute, remix, adapt, build upon this work non-commercially, and license their derivative works on different terms, provided the original work is properly cited, appropriate credit is given, any changes made indicated, and the use is non-commercial. See: http://creativecommons.org/licenses/by-nc/4.0/.

\section{ORCID iDs}

Matt Taberner http://orcid.org/0000-0003-3465-833X

Daniel D Cohen http://orcid.org/0000-0002-0899-4623

\section{REFERENCES}

1 Ekstrand J, Waldén M, Hägglund M. Hamstring injuries have increased by $4 \%$ annually in men's professional football, since 2001: a 13-year longitudinal analysis of the UEFA elite club injury study. Br J Sports Med 2016;50:731-7.

2 Schache AG, Dorn TW, Blanch PD, et al. Mechanics of the human hamstring muscles during sprinting. Med Sci Sports Exerc 2012;44:647-58.

3 Askling CM, Tengvar M, Saartok T, et al. Acute first-time hamstring strains during slow-speed stretching: clinical, magnetic resonance imaging, and recovery characteristics. Am J Sports Med 2007;35:1716-24.

4 Ayuob A, Kayani B, Haddad FS. Musculotendinous junction injuries of the proximal biceps femoris: a prospective study of 64 patients treated surgically. Am J Sports Med 2020;48:1974-82.

5 Anderson L, Close GL, Konopinski M, et al. case study: muscle atrophy, hypertrophy, and energy expenditure of a premier league soccer player during rehabilitation from anterior cruciate ligament injury. Int J Sport Nutr Exerc Metab 2019;29:559-66.

6 Close GL, Sale C, Baar K, et al. Nutrition for the prevention and treatment of injuries in track and field athletes. Int J Sport Nutr Exerc Metab 2019;29:189-97.

7 Shaw G, Lee-Barthel A, Ross ML, et al. Vitamin C-enriched gelatin supplementation before intermittent activity augments collagen synthesis. Am J Clin Nutr 2017;105:136-43.

8 McCall A, Nedelec M, Carling C, et al. Reliability and sensitivity of a simple isometric posterior lower limb muscle test in professional football players. J Sports Sci 2015;33:1298-304.
9 Read PJ, Turner AN, Clarke R, et al. Knee angle affects posterior chain muscle activation during an isometric test used in soccer players. Sports (Basel) 2019;7:13.

10 Taberner M, Cohen DD. Physical preparation of the football player with an intramuscular hamstring tendon tear: clinical perspective with video demonstrations. Br J Sports Med 2018;52:1275-78.

11 Jordan MJ, Morris N, Lane M, et al. Monitoring the return to sport transition after ACL injury: an alpine ski racing case study. Front Sports Act Living 2020;2:1-16.

12 Cohen DD, Burton A, Wells C, et al. Single v double leg countermovement jump tests; not half an apple. Aspetar Sports Med J 2020;9:34-41.

13 Glasgow P, Phillips N, Bleakley C. Optimal loading: key variables and mechanisms. Br J Sports Med 2015;49:278-79.

14 Arampatzis A, Peper A, Bierbaum S, et al. Plasticity of human Achilles tendon mechanical and morphological properties in response to cyclic strain. J Biomech 2010;43:3073-9.

15 Tillin NA, Pain MT, Folland JP. Short-term training for explosive strength causes neural and mechanical adaptations. Exp Physiol 2012;97:630-41.

16 Schaefer LV, Bittmann FN. Are there two forms of isometric muscle action? Results of the experimental study support a distinction between a holding and a pushing isometric muscle function. $B M C$ Sports Sci Med Rehabil 2017;9:11.

17 Bohm S, Mersmann F, Arampatzis A. Human tendon adaptation in response to mechanical loading: a systematic review and meta-analysis of exercise intervention studies on healthy adults. Sports Med Open 2015;1(1):7.

18 Bohm S, Mersmann F, Arampatzis A. Functional adaptation of connective tissue by training. Dtsch Z Sportmed 2019;70:105-110.

19 Macdonald B, O'Neill J, Pollock N, et al. The single-leg Roman chair hold is more effective than the Nordic hamstring curl in improving hamstring strength-endurance in Gaelic footballers with previous hamstring injury. J Strength Cond Res 2018;33:3302-8.

20 Macdonald B, McAleer S, Kelly S, et al. Hamstring rehabilitation in elite track and field athletes: applying the British athletics muscle injury classification in clinical practice. Br J Sports Med 2019;53:1464-73.

21 Opar DA, Williams MD, Timmins RG, et al. Knee flexor strength and bicep femoris electromyographical activity is lower in previously strained hamstrings. J Electromyogr Kinesiol 2013;23:696-703.

22 Kay D, St Clair Gibson A, Mitchell MJ, et al. Different neuromuscular recruitment patterns during eccentric, concentric and isometric contractions. J Electromyogr Kinesiol 2000;10:425-31.

23 Behm DG, Sale DG. Intended rather than actual movement velocity determines velocity-specific training response. J Appl Physiol 1993;74 359-68.

24 Heinemeier KM, Kjaer M. In vivo investigation of tendon responses to mechanical loading. J Musculoskelet Neuronal Interact 2011;11:115-23.

25 Khan KM, Scott A. Mechanotherapy: how physical therapists' prescription of exercise promotes tissue repair. $\mathrm{Br} J$ Sports Med 2009;43:247-52.

26 Kongsgaard M, Reitelseder S, Pedersen TG, et al. Region-specific patellar tendon hypertrophy in humans following resistance training. Acta Physiol 2007;191:111-21.

27 Hegyi A, Csala D, Péter A, et al. High-density electromyography activity in various hamstring exercises. Scand J Med Sci Sports 2019;29:34-43.

28 Taberner M, O'keefe J, Cohen DD. The sliding leg curl. Strength Cond 2016;38:117-21.

29 Brazier J, Maloney S, Bishop C, et al. Lower extremity stiffness: considerations for testing, performance enhancement, and injury risk. $J$ Strength Cond Res 2019;33:1156-66.

30 Prilutsky BI, Zatsiorsky VM. Tendon action of two-joint muscles: transfer of mechanical energy between joints during jumping, landing, and running. J Biomech 1994;27:25-34.

31 Timmins RG, Bourne MN, Shield AJ, et al. Short biceps femoris fascicles and eccentric knee flexor weakness increase the risk of hamstring injury in elite football (soccer): a prospective cohort study. $\mathrm{Br}$ J Sports Med 2016;50:1524-35.

32 Taberner M, Allen T, Cohen DD. Progressing rehabilitation after injury: consider the 'control-chaos continuum'. Br J Sport Med 2019;53:1132-36.

33 Hegyi A, BAM G, Finni T, et al. Individual region- and muscle-specific hamstring activity at different running speeds. Med Sci Sports Exerc 2019;51:2274-85.

34 Van Hooren B, Bosch F. Is there really an eccentric action of the hamstrings during the swing phase of high-speed running? Part II: implications for exercise. J Sports Sci 2017;35:2322-33.

35 Woods C, Hawkins RD, Maltby S, et al. The football association medical research programme: an audit of injuries in professional football: analysis of hamstring injuries. Br J Sports Med 2004;38:36-41.

36 Kijowksi KN, Capps CR, Goodman CL, et al. Short-term resistance and plyometric training improves eccentric phase kinetics in jumping. J Strength Cond Res 2015;29:2186-96. 